\title{
Many-Valued Logics for Modeling Vagueness
}

\author{
Supriya Raheja \\ ITM University \\ Gurgaon, India
}

\author{
Reena Dhadich \\ Govt. Engg. College \\ Ajmer, India
}

\begin{abstract}
Many-Valued logics have been developed to represent mathematical model of imprecision, vagueness, uncertainty and ambiguity in the information. In real world each and every species is vague, human knowledge and the natural languages have a bunch of vagueness or imprecise information. This paper attempts to present three main theories of many-valued logics to treat the vagueness: Fuzzy Logic, Vague Logic and Neutrosophic Logic. Author touches the various perspectives logical, algebraic operation, graphical representations and the practical usage. This paper addresses the modeling of vagueness.
\end{abstract}

Author introduces the framework, Vague Inference System (VIS) for modeling the vagueness using vague logic.

\section{Keywords}

Fuzzy Logic (FL), Vague Logic (VL), Neutrosophic Logic (NL), Membership functions, Vague Inference System (VIS)

\section{INTRODUCTION}

In the Classical Set Theory introduced by Cantor, values of elements in a set are only two possibilities: either exists or not exist in the set. The theory cannot handle the ambiguity and uncertainty. Theories of Fuzzy sets, Vague sets and Neutrosophic sets are the generalizations of Classical Set Theory for treating vagueness and uncertainty. A sentence is vague if and only if the sentence is neither absolutely true nor absolutely false. Fuzzy logic has been essential means of implementing machine intelligence. Therefore, Fuzzy Logic cannot be ignored in order to bridge the gap between natural language and machine language.

Fuzzy Logic (FL), one form of many-valued logic was conceived by Prof. Lotfi Zadeh [1]. It deals with the imprecise information, as a way of treating data by permitting partial set membership rather than crisp set membership. In FL the value (degree) for the Linguistic variables can be ranging between 0 and 1 . When the Linguistic variables are used, these degrees may be dealt by specific functions called membership functions. Fuzzy Logic represents the "degrees of truth". For example, let consider a person with 33 years old. Someone can consider him as "old" and the other one can consider him as the "young". The degree of membership varies from person to person.

In Fuzzy Set Theory, each element $x \in U$ (Universe of discourse) is assigned a single membership value. Gau [4] point out that the single membership value contains the evidences for both favoring and opposing $\mathrm{x}$. It cannot treat the two evidences individually, even cannot treat the two evidences at the same duration.

In order to solve this problem, Gau and Buehrer introduced notion of Vague set [4] which allows the interval based membership function over point based membership function. It is the further generalization of Fuzzy Set Theory. The Vague set theory becomes a promising tool to deal with imprecise, uncertain or vague knowledge with improved performance but having complex problem solution.

Later on Intuitionistic Fuzzy Sets [2] and Interval Valued Intuitionistic Fuzzy Sets were introduced. These sets can only handle incomplete information not the indeterminate information and inconsistent information. To handle the indeterminate data, Florentine Smarandache introduced the notion of Neutrosophic logic [7] which is again the manyvalued logic based on Neutrosophy. As a generalization of Fuzzy Logic, in Neutrosophic Logic indeterminacy is included. Fuzzy theory has failed when the relations are indeterminate. The inclusion of indeterminate information with Fuzzy Logic is nothing but the Neutrosophic Logic.

To implement the machine intelligence, it is often needed to compare the different many-valued logics. This paper is written with the aim of collecting the three main theories of many-valued logic at one place. As these theories have many facets: the logical facet, the set-theoretic facet and the graphical facet. Firstly author discusses the notions of Fuzzy, Vague and Neutrosophic Sets. Then, Author presents the set theoretic operations with respect to the mentioned set theories. After this Author includes the graphical representation of membership functions associated with linguistic variables. Lastly Author addresses the modeling of vagueness in which author proposes the framework to model the vagueness using Vague Logic.

\section{BASIC CONCEPT}

In this section author briefly recall the basic definition and the graphical representation of membership functions of Fuzzy Set, Vague set and the Neutrosophic Set. Let $\mathrm{U}$ be a Universe of Discourse, where an element of $\mathrm{U}$ is denoted by $\mathrm{x}$.

\subsection{Definitions}

Definition1. (Fuzzy Set) A fuzzy set $A=\left\{<x, \mu_{A}(x)>\mid x \in\right.$ $\mathrm{U}\}$ in a universe of discourse $\mathrm{U}$ is characterized by a membership function, $\mu_{\mathrm{A}}$, as follows:

$$
\mu_{\mathrm{A}}: U \rightarrow[0,1] \text {. }
$$

Definition2. (Vague Set) A Vague set V in a universe of discourse $U$ is characterized by a true membership function, $t_{V}$ and a false membership function, $\mathrm{f}_{\mathrm{V}}$, as follows:

$$
\begin{aligned}
& \mathrm{t}_{\mathrm{V}}: \mathrm{U} \rightarrow[0,1], \\
& \mathrm{f}_{\mathrm{V}}: \mathrm{U} \rightarrow[0,1],
\end{aligned}
$$

$t_{V}(x)+f_{V}(x) \leq 1$, where $t_{V}(u)$ is a lower bound on the grade of membership of $x$ derived from the evidence for $x$, and $f_{V}$ (u) is a lower bound on the grade of membership of the negation of $\mathrm{x}$ derived from the evidence against $\mathrm{x}$.

Definition3. (Neutrosophic Set) A Neutrosophic set N defined on universe $U . x=x(t, i, f) \in N$ with $t, i$ and $f$ being the real standard or non-standard subsets of $] 0-, 1+[. t$ is the degree of true-membership function, $i$ is the degree of indeterminate- 
membership function and $\mathrm{f}$ is the degree of false-membership function in the set $\mathrm{N}$.

\subsection{Graphical Representation of Membership Functions}

Figure 1 represents the graphical representation of fuzzy membership function whose values lie between 0 to1. There can be different type of membership functions, triangular, trapezoidal, Gaussian, sig and many more.

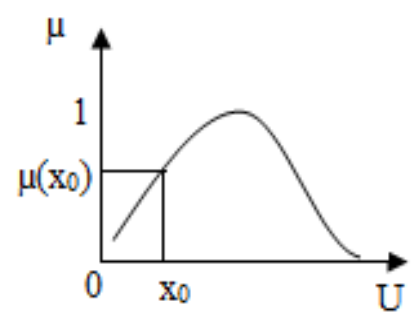

Fig 1 Fuzzy Membership Function

Figure 2 represents the membership functions (tv and fv) associated with the vague set variable. The region that comes between Support and Against Region is the Hesitation region. The total scope of these regions is between 0 to1 i.e. Against Region + Support Region + Hesitation Region $=1$.

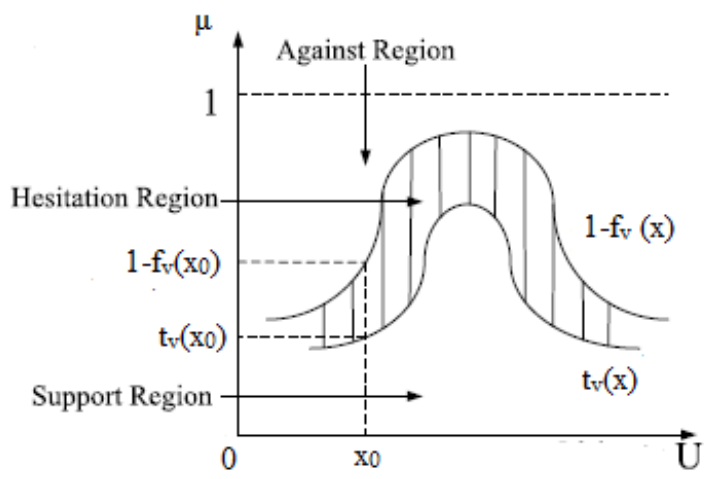

Fig 2 Vague Membership Function

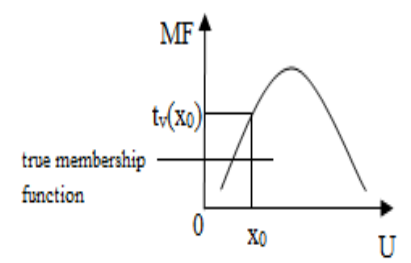

Fig 3(a) Neutrosophic true-membership function

Figure 3 represents the Neutrosophic membership functions (true, indeterminate and false) respectively. Author has represented separately all these function because there are no boundary constraints in the Neutrosophic logic.

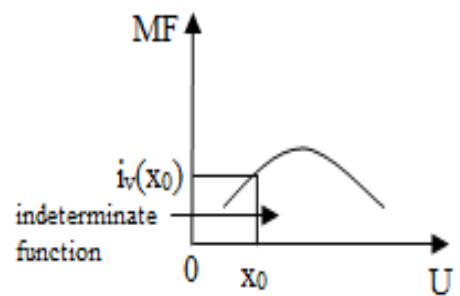

Fig 3(b) Neutrosophic intermediate-membership function

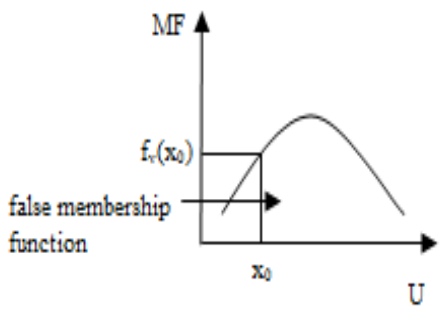

Fig 3(c) Neutrosophic false-membership function

\section{ALGEBRAIC OPERATIONS}

There are many definitions for logic connectives when considering many-valued Logic. Likewise, there are definitions for Fuzzy Set, Vague set and for Neutrosophic Set.

In this section we present the basic algebraic operations on the respective set theories. It includes Union, Intersection and complement.

\subsection{Fuzzy Set Operations}

Let $\mathrm{A}, \mathrm{B}, \mathrm{C}$ be three fuzzy sets with membership functions $\mu_{\mathrm{A}}$, $\mu_{\mathrm{B}}$ and $\mu_{\mathrm{C}}$ respectively defined on the universe of discourse $\mathrm{U}$. The operations for all $\mathrm{x}$ are as follows:

Definition4. (Complement) The complement of a Fuzzy set A is defined by

$$
\mu_{\mathrm{A}^{\prime}}(\mathrm{x})=1-\mu_{\mathrm{A}}(\mathrm{x})
$$

Definition5. (Union) The union of two fuzzy sets $\mathrm{A}$ and $\mathrm{B}$ is a fuzzy set $\mathrm{C}$, written as $\mathrm{C}=\mathrm{A} \cup \mathrm{B}$, is defined by

$$
\mu_{\mathrm{C}}(\mathrm{x})=\max \left(\mu_{\mathrm{A}}(\mathrm{x}), \mu_{\mathrm{B}}(\mathrm{x})\right)
$$

Definition6. (Intersection) The intersection of two fuzzy sets $\mathrm{A}$ and $\mathrm{B}$ is a fuzzy set $\mathrm{C}$, written as $\mathrm{C}=\mathrm{A} \cap \mathrm{B}$, is defined by

$$
\mu_{\mathrm{C}}(\mathrm{x})=\min \left(\mu_{\mathrm{A}}(\mathrm{x}), \mu_{\mathrm{B}}(\mathrm{x})\right)
$$

\subsection{Vague Set Operations}

Let $\mathrm{A}, \mathrm{B}, \mathrm{C}$ be three vague sets with true membership and false membership functions $t_{A}, f_{A}, t_{B}, f_{B}$ and $t_{C}, f_{C}$ respectively defined on the universe of discourse $\mathrm{U}$. The operations for all $\mathrm{x}$ are as follows:

Definition7. (Complement) The complement of a vague set A is defined by

$$
\begin{aligned}
& t_{A^{\prime}}(x)=f_{A}(x) \\
& 1-f_{A^{\prime}}(x)=1-t_{A}(x)
\end{aligned}
$$


Definition8. (Union) The union of two vague sets $\mathrm{A}$ and $\mathrm{B}$ is a vague set $C$, written as $C=A \cup B$, is defined by

$$
\begin{aligned}
& \mathrm{t}_{\mathrm{C}}(\mathrm{x})=\max \left(\mathrm{t}_{\mathrm{A}}(\mathrm{x}), \mathrm{t}_{\mathrm{B}}(\mathrm{x})\right) \\
& 1-\mathrm{f}_{\mathrm{C}}(\mathrm{x})=1-\min \left(\mathrm{f}_{\mathrm{A}}(\mathrm{x}), \mathrm{f}_{\mathrm{B}}(\mathrm{x})\right)
\end{aligned}
$$

Definition9. (Intersection) The intersection of two vague sets $\mathrm{A}$ and $\mathrm{B}$ is a vague set $\mathrm{C}$, written as $\mathrm{C}=\mathrm{A} \cap \mathrm{B}$, is defined by

$$
\begin{aligned}
& t_{C}(x)=\min \left(t_{A}(x), t_{B}(x)\right) \\
& 1-f_{C}(x)=1-\max \left(f_{A}(x), f_{B}(x)\right)
\end{aligned}
$$

\subsection{Neutrosophic Set Operations}

Let A, B, C be three Neutrosophic sets with true membership, indeterminacy and false membership functions $t_{A}, i_{A}, f_{A}, t_{B}, i_{B}$, $f_{B}$ and $t_{C}, i_{C}, f_{C}$ respectively defined on the universe of discourse $\mathrm{U}$. The operations for all $\mathrm{x}$ are as follows:

Definition10. (Complement) The complement of a Neutrosophic set A is defined by

$$
\begin{aligned}
& \mathrm{t}_{\mathrm{A}^{\prime}}(\mathrm{x})=\{1+\}-\mathrm{t}_{\mathrm{A}}(\mathrm{x}) \\
& \mathrm{i}_{\mathrm{A}^{\prime}}(\mathrm{x})=\{1+\}-\mathrm{i}_{\mathrm{A}}(\mathrm{x}) \\
& \mathrm{f}_{\mathrm{A}^{\prime}}(\mathrm{x})=\{1+\}-\mathrm{f}_{\mathrm{A}}(\mathrm{x})
\end{aligned}
$$

Definition11. (Union) The union of two Neutrosophic sets A and $B$ is a Neutrosophic set $C$, written as $C=A \cup B$, is defined by

$$
\begin{aligned}
& t_{C}(x)=t_{A}(x)+t_{B}(x)-t_{A}(x) \times t_{B}(x) \\
& i_{C}(x)=i_{A}(x)+i_{B}(x)-i_{A}(x) \times i_{B}(x) \\
& f_{C}(x)=f_{A}(x)+f_{B}(x)-f_{A}(x) \times f_{B}(x)
\end{aligned}
$$

Definition12. (Intersection) The intersection of two Neutrosophic sets A and B is a Neutrosophic set C, written as $\mathrm{C}=\mathrm{A} \cap \mathrm{B}$, is defined by

$$
\begin{aligned}
& \mathrm{t}_{\mathrm{C}}(\mathrm{x})=\mathrm{t}_{\mathrm{A}}(\mathrm{x}) \times \mathrm{t}_{\mathrm{B}}(\mathrm{x}) \\
& \mathrm{i}_{\mathrm{C}}(\mathrm{x})=\mathrm{i}_{\mathrm{A}}(\mathrm{x}) \times \mathrm{i}_{\mathrm{B}}(\mathrm{x}) \\
& \mathrm{f}_{\mathrm{C}}(\mathrm{x})=\mathrm{f}_{\mathrm{A}}(\mathrm{x}) \times \mathrm{f}_{\mathrm{B}}(\mathrm{x})
\end{aligned}
$$

\section{VAGUENESS IN PRACTICAL USAGE}

In this section we review the interpretations of membership functions by considering different examples.

Consider a vague predicate "Allen is tall" represented by $\mu$ (Allen) $=0.8$ as shown in Figure 4. According to Fuzzy definition $80 \%$ people says Allen is tall.

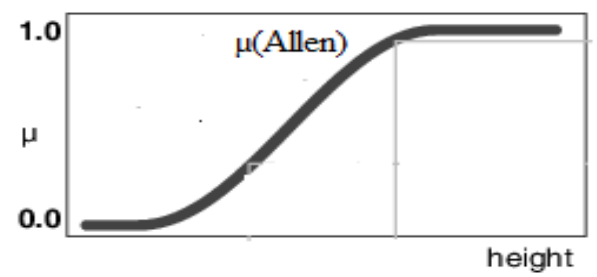

Fig 4 Membership function for tall

Since this definition includes both the evidence for $\mathrm{u}$ and evidence against $\mathrm{u}$. Consider the same predicate by $[0.6,0.8]$. According to vague definition $60 \%$ people says Allen is tall and $20 \%$ says Allen is not tall. Remaining $20 \%$ are in hesitation region.
When the predicate is represented as $[0.6,0.3,0.5]$, is interpretive as $60 \%$ people says Allen is tall, $30 \%$ people are not sure about the tallness of Allen and the $50 \%$ people says Allen is not tall. Neutrosophic representation includes the indeterminacy of the vagueness of predicate i.e. $30 \%$ in this case. Human beings have their limitation of perception, judgment, and processing-capability in real life situations. In the case of fuzzy set, there is no higher order check for this single membership value [4].

Suppose there are 30 citizens during a voting process. At some time, 18 votes for "yes", 7 votes for "no" and 5 are "undecided". Using Neutrosophic notation, it can be expressed as $\mathrm{x}(0: 18 ; 0: 5 ; 0: 7)$. Using fuzzy it is not possible to separate the voting process in favour or against. Using Vague notation we can separate the votes in favour or votes in against but with constraint $t_{v}+f_{v} \leq 1$. Neutrosophic Notation has no restrictions on the boundary. In Neutrosophic Set, indeterminacy is quantified explicitly and true-membership, indeterminacy-membership and false-membership are independent. This assumption is very important in many applications.

The above examples indicate that Neutrosophic set is more natural than the vague set and vague set performance is better than the Fuzzy Set. But it is not possible to implement all the fuzzy based applications in vague set or in Neutrosophic Set [9].

\section{MODELING OF VAGUENESS}

This section presents how the vagueness can be modeled using Fuzzy Logic and the Neutrosophic Logic. There is no reference in the literature for modeling of vagueness using Vague Logic. In this section author proposes the new framework, Vague Inference System to model the vagueness using Vague Logic.

\subsection{Modeling of Vagueness Using FL}

The key unit of the Fuzzy Logic system is Fuzzy Inference System (see Figure 5). The main task of this system is decision making. Fuzzy inference is the process of articulating the mapping from a given input to an output using fuzzy logic. This mapping provides a base for decisions to be made.

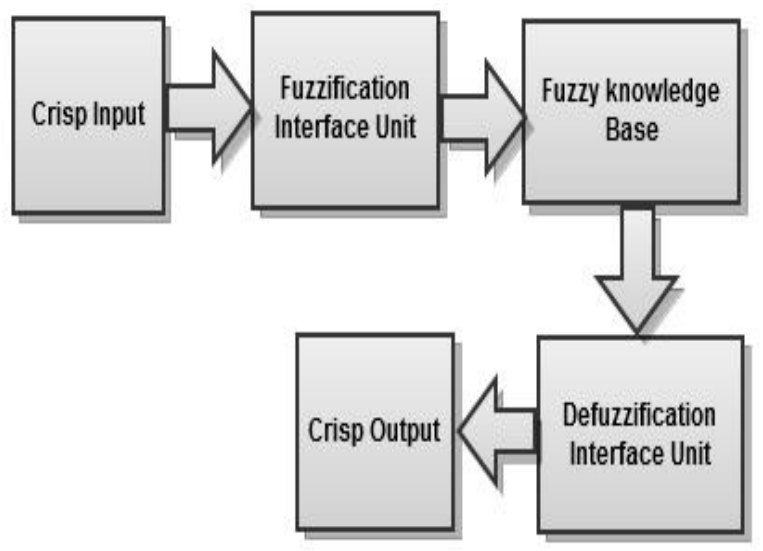

Fig 5 Fuzzy inference system

\subsection{Modeling of Vagueness Using NL}

In this author discusses the Neutrosophic inference system to model the vagueness using Neutrosophic logic. In the referenced model the Neutrosophication unit accepts the crisp input and assigns the appropriate membership functions 
(truth-membership function, indeterminacy membership function, falsity-membership function). After this, input variables are mapped to output variable in Neutrosophic inference Engine using the Neutrosophic rule base. The resulting Neutrosophic value is mapped to crisp value in Deneutrosophication step.

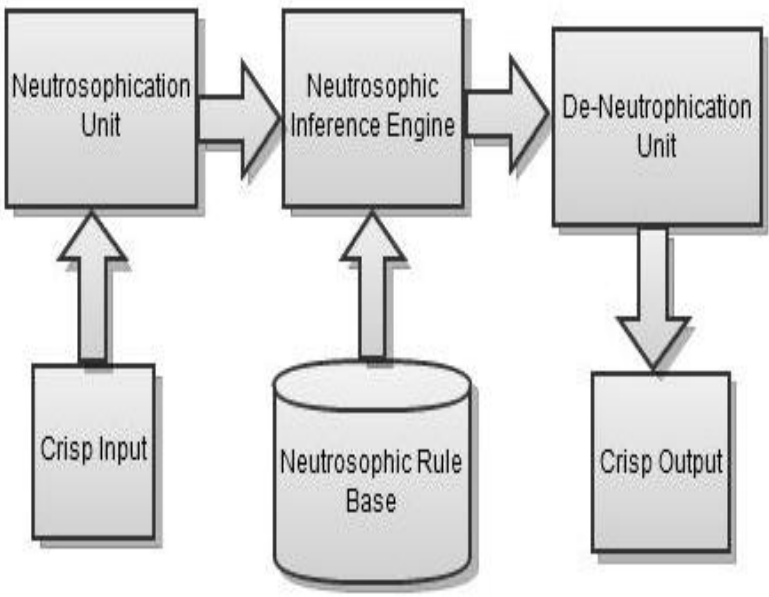

Fig 6 Neutrosophic Inference System

\subsection{Modeling of Vagueness Using VL}

In this paper author proposes a new framework which adopts the Fuzzy Inference System to construct a Vague Inference System.

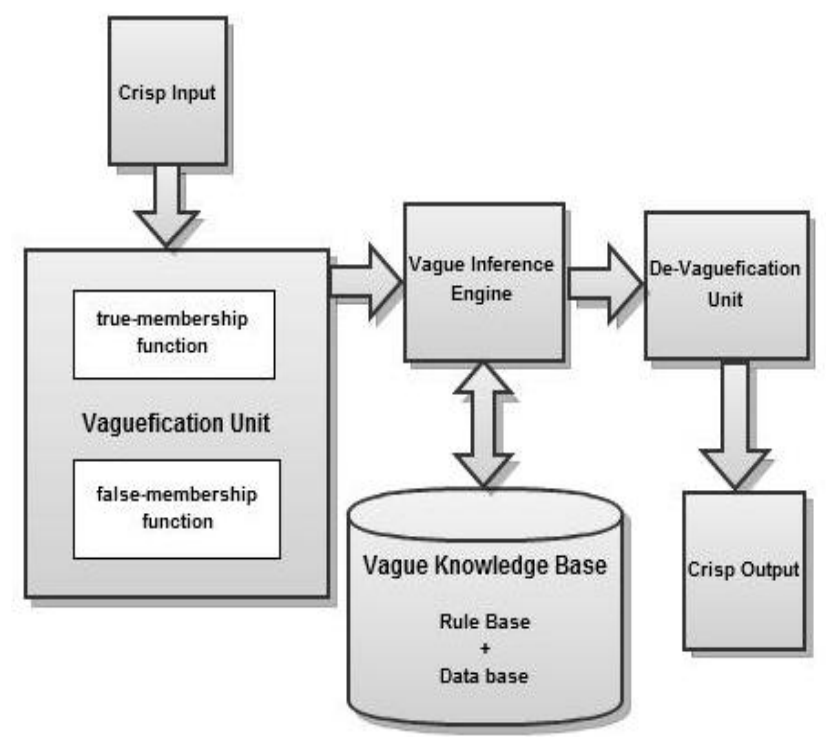

Fig 7 Vague Inference System

Vague Inference System (VIS) constitutes 4 main components:
a) Vaguefication Unit
b) Vague Inference Engine
c) Vague Rule Base
d) De-Vaguefication Unit

Vaguefication Unit: modeling perpetually involves a process called Vaguefication. Vaguefication is a mathematical procedure for converting an element in the universe of discourse into the membership value of the vague set. Vaguefication Unit contains the true-membership function and the false-membership function. It takes the crisp inputs and converts into appropriate vague sets using true and false membership functions stored in the Vague Knowledge Base. Suppose vague set $\mathrm{V}$ is defined on the universe of discourse $\mathrm{U}$; for any $\mathrm{x} \in \mathrm{U}$, the result of vaguefication is simply $\mathrm{t}_{\mathrm{v}}(\mathrm{x})$ and $1-f_{v}(x)$.Vaguefication unit considers the constraint $\mathrm{t}_{\mathrm{v}}(\mathrm{x})+\mathrm{f}_{\mathrm{v}}(\mathrm{x}) \leq 1$.

Vague Inference Engine: The evaluations of the rules and the combination of results are performed using Vague Set operations. After this, Vague Inference Engine evaluates the rules stored in the Vague Rule Base.

Vague Rule Base: A VIS implements a mapping from its input to output. This mapping is performed by number of IfThen type vague rules (with respect to true membership functions and false membership functions). Antecedent of a rule defines a vague region (Support Region and Against Region) in the input space, while the consequent specifies the output in the vague region. After the vague inference step, the final result will be a vague set or multiple vague sets which would be defined on the universe of possible actions.

De-Vaguefication Unit: To obtain the crisp output the vague values should be converted into crisp value. This is the task of De-Vaguefication unit. It performs the action according to the specified true and false membership functions of the output variable.

\section{CONCLUSION}

Author examined the three theories of many-valued logic: Fuzzy, vague and Neutrosophic Logic on the various perspectives. Neutrosophic sets are the most expressive way to capture the vagueness of data over the vague set due to the inclusion of indeterminate function. Vague sets are the more expressive way to model the vagueness of data over fuzzy set due to the separation of true and false membership functions that provides the evidence for favour and evidence for against. Author compared many-valued logic by their notions, algebraic operations, practical usage, and most importantly, the graphical representations of membership functions. Author has shown in practical usage by examples, using a Neutrosophic Set is more natural than using a vague Set or Fuzzy Set. Author has also discussed the modeling of vagueness with fuzzy logic and the Neutrosophic Logic. Author has introduced a framework Vague Inference System (VIS) to model the Vague Logic, which adopts the Fuzzy Inference System. In future Author will try to implement the various applications using the Vague Inference System.

\section{REFERENCES}

[1] L. A. Zadeh, "Fuzzy sets", Information and Control, 8:338-356, 1965

[2] K. Atanassov, "Intuitionistic fuzzy sets", Fuzzy Sets and Systems, 20:87-96, 1986.

[3] K. Atanassov, "Intuitionistic Fuzzy Sets: Theory and Applications", Physica-Verlag, New York, 2000.

[4] W. L. Gau and D. J. Buehrer, "Vague sets", IEEE Transaction on systems, Man and Cybernetics, 23:610 614, 1993.

[5] V. Novak, I. Perfilieva, J. Mochkorg, "Mathematical principles of vague logic", (In Russian) FIZMATLIT, Moskow, (2006) 352 .

[6] Bustince H. and Burillo P., "Vague sets are intuitionistic fuzzy sets", Fuzzy Sets and Systems 79 (1996) 403-405. 
[7] F. Smarandache (2002a), A unifying Field in Logics: Neutrosophic Logic, in Multiple- Valued Logic / An International Journal, Vol. 8, No. 3, 385- 438, 2002.

[8] C. Ashbacher, Introduction to Neutrosophic Logic, Am. Res. Press, Rehoboth, USA, 2002.
[9] Umberto Rivieccio, Neutrosophic logics: Prospects and problems, in Fuzzy Sets and Systems, Vol. 159, Issue 14, pp. $1860-1868,2008$. 